Check for updates

Cite this: RSC Adv., 2018, 8, 1909

Received 3rd September 2017

Accepted 28th December 2017

DOI: 10.1039/c7ra09804a

rsc.li/rsc-advances

\section{Exploring corrosion protection properties of alkydalanthanide bis-phthalocyanine nanocomposite coatings}

\author{
M. A. Deyab, (DD *a R. Stota, ${ }^{b}$ E. Bloise ${ }^{c}$ and G. Mele (DD *c
}

Organic coatings have been widely used to protect carbon steel pipelines from external corrosion; however, they often suffer from permeability and weak adhesion. Here we show that synthetic lanthanide bis-phthalocyanine complexes, $\mathrm{LnPC}_{2}$ ( $\mathrm{Ln}=$ lanthanide metal, $\mathrm{Pc}=\mathrm{C}_{32} \mathrm{H}_{16} \mathrm{~N}_{8}$ denotes the phthalocyanine ligand) can be used to form new nanocomposite coatings to provide corrosion protection to the underlying carbon steel pipelines. Electrochemical studies (EIS and potentiodynamic polarization) showed that the incorporation of $\mathrm{LnPc}_{2}$ compound $\left(\mathrm{PrPc}_{2}, \mathrm{SmPc}_{2}\right.$ and $\left.\mathrm{HoPc}_{2}\right)$ additives with alkyd coating, leads to a significant increase in the corrosion resistance of carbon steel in $0.5 \mathrm{M} \mathrm{HCl}$ solution. The alkyd@ $\mathrm{LnPC}_{2}$ nanocomposite coatings absorb very low water volumes, when compared to the neat alkyd coating. $\mathrm{LnPC}_{2}$ compounds allowed enhancing the pull-off adhesion of coatings performance from 3.34 MPa to $19.94 \mathrm{MPa}$. The efficiency of alkyd@ HoPc $\mathrm{C}_{2}$ coating appears higher than that of alkyd $a \mathrm{PrPc}_{2}$ and alkyd@ $\mathrm{SmPC}_{2}$ coatings. The protective properties of alkyd@ $\mathrm{LnPC_{2 }}$ coatings were confirmed by SEM, TGA, scratch hardness, impact resistance, bend test and contact angle analysis.

\section{Introduction}

The best approach to guaranteeing the protection of carbon steel pipelines is to hinder corrosion before it occurs, and organic coatings have long been used for that goal. ${ }^{1-4}$ Organic coatings protect carbon steel pipelines against corrosion by forming a physical barrier that prevents oxygen, water and corrosive ions from reaching the surface of the pipelines.,

The two major drawbacks of organic coatings are coating permeability and weak adhesion. ${ }^{7}$ Augmenting the adhesion of the organic coating and decreasing the resin pore channels improve the overall performance of the coatings. This extra shielding is typically achieved by incorporating nano sized pigments, which decrease the coating permeability and enhance the coating adhesion..$^{8-10}$

Recent years have witnessed many efforts to increase the corrosion protection efficiency of organic coating by formation nano-composites formulas. ${ }^{\mathbf{1 1 , 1 2}}$ These efforts include adding inorganic and organic particles. ${ }^{13-15}$ Our previous contribution in this field was the application of metal phthalocyanine pigments to improve the corrosion protection performance of the epoxy/metallophthalocyanine nanocomposite coatings. ${ }^{16}$ In the present study, lanthanide metal bis-phthalocyanine

${ }^{a}$ Egyptian Petroleum Research Institute (EPRI), PO Box 11727, Nasr City, Cairo, Egypt. E-mail: hamadadeiab@yahoo.com

${ }^{b}$ Faculty of Chemistry, Opole University, ul. Oleska 48, 45-052 Opole, Poland

${ }^{c}$ Department of Engineering for Innovation of University of Salento, via Arnesano, 73100, Lecce, Italy. E-mail: giuseppe.mele@unisalento.it complexes $\left(\mathrm{LnPc}_{2}\right)$ had been used to obtain novel nanocomposite coatings to provide excellent corrosion protection to the underlying carbon steel pipelines. The investigation of the new materials performance involved electrochemical, water permeability and pull-off adhesion SEM, TGA, scratch hardness, impact resistance, bend test and contact angle analysis.

\section{Methods}

\subsection{Materials}

Carbon steel plates (supplied from Alex. National Iron and Steel Co.) with the following composition (wt\%): $0.02 \mathrm{Cu} ; 0.012 \mathrm{Ni}$; 0.7 Mn; 0.005 P; 0.06 C; 0.001 S; 0.002 V; 0.004 Mo; 0.015 Cr; 0.06 $\mathrm{Si}$ and balanced $\mathrm{Fe}$, were employed as metallic substrates.

Alkyd resin (middle oil length resin, solid content $=50 \%$, viscosity $=2000 \mathrm{mPa} \mathrm{s}$, ATCOAT company), the hardener (isophoronediamine, BASF Co.) and xylene (Purechem Co.) were industrial grade materials and were used as purchased. Hydrochloric acid (35\%) used in the study were purchased from Sigma-Aldrich.

\subsection{Synthesis of $\mathrm{LnPc}_{2}$}

The $\mathrm{LnPc}_{2}$ complexes ( $\left.\mathrm{Ln}=\mathrm{Pr}, \mathrm{Sm}, \mathrm{Ho}\right)$ were all synthesized at the Faculty of Chemistry, Opole University (Poland) according to an original procedure reported elsewhere. ${ }^{17}$ The lanthanide metals (Ln) typically form double-decker complexes including the trivalent $\operatorname{Ln}(3+)$ ion sandwiched between two phthalocyanine ligands. The molecular structure of $\mathrm{LnPc}_{2}$ along with some average size 
data have been shown in Fig. 1 and the compounds identity was previously confirmed by UV-Vis and FTIR spectroscopy. ${ }^{17}$

\subsection{Preparation of alkyd@LnPc $c_{2}$ nanocomposite coatings}

The solvent (xylene), $\mathrm{LnPc}_{2}$ powder (1.0\%) and dispersant agent (Polyetherphosphate, Evonik Nutrition \& Care $\mathrm{GmbH}$ ) were mixed and ground to avoid the agglomeration of nanoparticles. Such prepared mixture was incorporated into the alkyd resin (75\%). The final composite was mixed using a high speed mechanical stirrer followed by ultrasonication $(1 \mathrm{~h})$ and then ground for $2 \mathrm{~h}$ to obtain the desired fineness. The hardener was added to the coating composite in the ratio of $1: 3$.

The carbon steel plates were cut into $3.0 \times 1.5 \mathrm{~cm}^{2}$ pieces. The test plates were pre-treated by mechanical cleaning, degreasing in acetone and rinsing with distilled water before being coated. The nanocomposite coatings were applied on the surface by dip-coating on pretreated carbon steel plates. The dry film thicknesses of the coatings $(35 \pm 10 \mu \mathrm{m})$ were measured by a micrometer (B.C. Ames Co.). For the sake of comparison, a number of experiments were conducted with the neat alkyd coating only, without the addition of $\mathrm{LnPc}_{2}$.

\subsection{Electrochemical experiments}

Electrochemical experiments were recorded in 3 electrodes mode using an ACM potentiostat (Gill AC) controlled with the ZView program software. A platinum mesh was used as counter electrode and the reference electrode was a saturated calomel electrode (SCE) and all potentials were referenced versus the SCE.

EIS measurements were conducted after 7 days of immersion, at open circuit potential (OCP) in the frequency range of 30 $\mathrm{kHz}$ to $0.01 \mathrm{~Hz}$, with perturbation amplitude of $10 \mathrm{mV}$.

The potentiodynamic polarization experiments were carried out in the potential range of $(-250 \mathrm{mV})$ to $(+250 \mathrm{mV}) v s$. OCP with a sweep rate of $0.166 \mathrm{mV} \mathrm{s}^{-1}$.

Each experiment was repeated at least three times under practically identical conditions to provide good reproducibility for the results.

\subsection{Characterization experiments}

The morphology of the selective samples before and after the corrosion analysis was observed using a scanning electron microscopy (SEM: JEOL).
Pull-off adhesion tester (PAT model GM01/6.3 kN) was used to investigate the adhesion strength of coatings according to the ASTM D4541 standard method.

Scratch hardness for coatings was performed according to ASTM D7027 using Elcometer 3025 Scratch/Shear Tester.

Impact resistance for coatings was performed according to ASTM D2794 using BYK-Gardner ISO Impact Tester.

The bend test was performed in accordance with ASTM D522 using TQC Bend Test Conical Mandrel.

The contact angle test between water and coatings surface was measured using OCA 15EC (Dataphysics) in accordance with ASTM D7334.

The TGA analysis of the coatings was carried out using TGA 550 TA Instruments in accordance with ASTM E1131, within the temperature range $10-800{ }^{\circ} \mathrm{C}$, at a heating rate of $10{ }^{\circ} \mathrm{C} \mathrm{min}^{-1}$ in a nitrogen atmosphere.

\section{Results and discussion}

\subsection{Electrochemical studies}

Fig. 2 depicts the electrochemical impedance spectroscopy approach (Nyquist and Bode module) used to study the influence of $\mathrm{LnPc}_{2}$ on the corrosion performance of nanocomposite coatings. The EIS plots (Fig. 2) were recoded for carbon steel coated with the alkyd resin only and when including the $\operatorname{PrPc}_{2}$, $\mathrm{SmPc}_{2}$ and $\mathrm{HoPc}_{2}$, after 7 days of storage in $0.5 \mathrm{HCl}$ solution at $298 \mathrm{~K}$.

Generally, a carbon steel surface protected with an undamaged coating layer has very high impedance values. The neat alkyd coating degrades with time, resulting in more complex impedance behavior. The Nyquist plot for neat alkyd coating is characterized by two well-defined time constants (see Fig. 2). After a certain period of time, the electrolyte penetrates into the coating and forms a new liquid/metal interface under the coating. ${ }^{18}$ A corrosion process can occur at this new interface. ${ }^{19}$ The simple equivalent circuit for neat alkyd coating was schematized in Fig. $3 .^{20}$ In this equivalent circuit, $R_{\mathrm{S}}$ is the solution resistance, $C_{\mathrm{c}}$ represents the capacitance of the intact coating, $R_{\text {po }}$ (pore resistance) is the resistance of ion conducting paths that have been developed within the coating. On the carbon steel surface side, the corrosive solution penetrates through the defective neat alkyd coating. The interface between this corrosive solution and the surface of carbon steel is modeled as

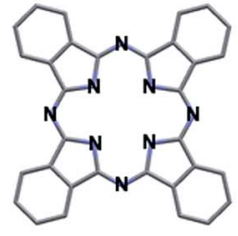

(a)

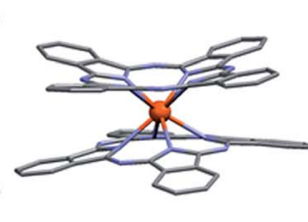

(b)

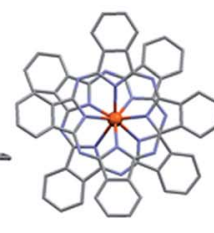

(c)

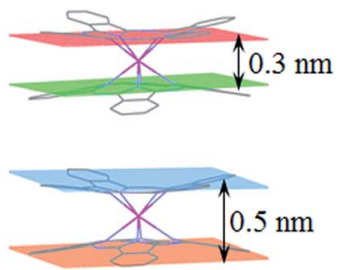

(d)

Fig. 1 (a) The phthalocyanine macrocycle $\left(\mathrm{PC}=\mathrm{C}_{32} \mathrm{H}_{16} \mathrm{~N}_{8}\right.$ ) with $\mathrm{N}$ atoms highlighted; framework size $1.3 \times 1.3 \mathrm{~nm}{ }^{2}$. (b) $\mathrm{LnPC}_{2}$ double-decker molecular structure side view, and (c) top view; (d) maximum distances, between planes determined (top) by the inner pyrrole nitrogen atoms and (bottom) between planes determined by the outer benzene ring frames (estimated based on original Cambridge Crystallographic Data files). 

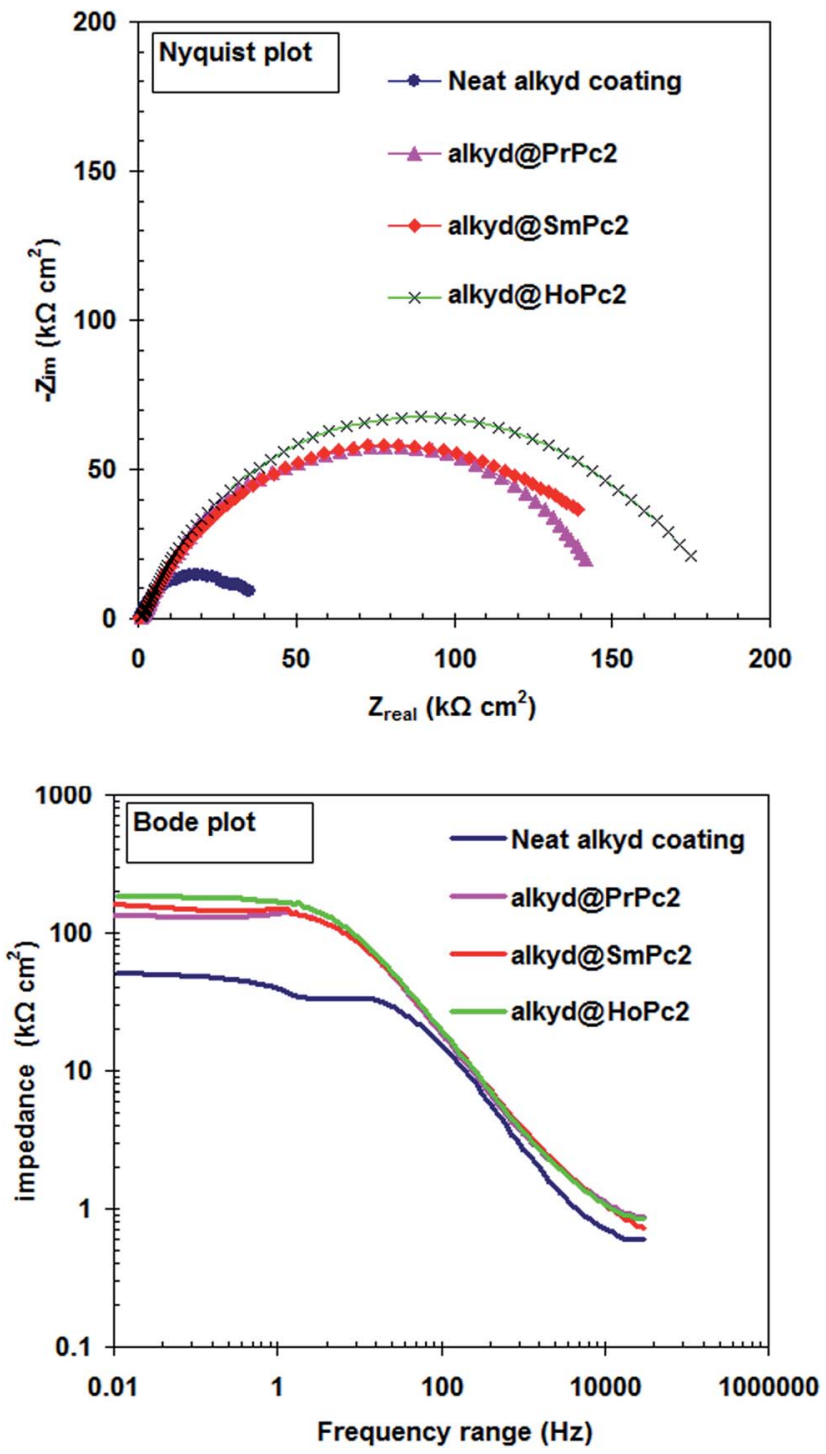

Fig. 2 EIS plots for the carbon steel coated with the alkyd resin only and when including the $\mathrm{LnPC}_{2}$ after 7 days of storage in $0.5 \mathrm{M} \mathrm{HCl}$ solution at $298 \mathrm{~K}$.

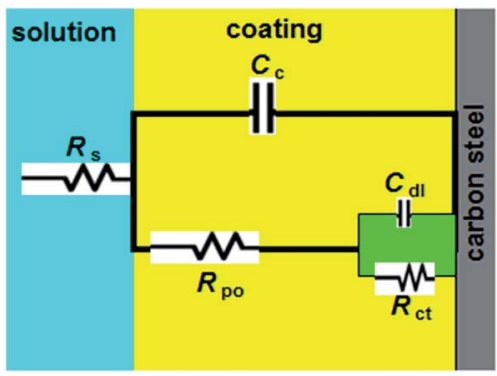

Fig. 3 Equivalent circuit for the neat alkyd coating

a double layer capacity $\left(C_{\mathrm{dl}}\right)$ in parallel with charge transfer resistance $\left(R_{\mathrm{ct}}\right)$. All the equivalent circuit parameters are listed in Table 1. The total impedance at low frequency is the sum of $R_{\mathrm{s}}, R_{\mathrm{po}}$ and $R_{\mathrm{ct}}$, while the total impedance at the point between two semi-circles is the sum of $R_{\mathrm{S}}$ and $R_{\mathrm{po}}{ }^{21}$ The semi-circle in the high frequency region is due to the coating film and the second semi-circle at the low frequency region is due to the double layer capacitance. ${ }^{22}$

Upon incorporating of the $\mathrm{LnPc}_{2}$ additives with alkyd coating, a high performance coating with excellent barrier properties was formed. At this stage, $R_{\mathrm{po}}$ is extremely high. In this case, the Nyquist plot exhibits the characteristic semi-circle of a Randles-like cell which may be due to the resistance and capacitance of the coating (see Fig. 4).

When comparing the $R_{\mathrm{po}}$ and $C_{\mathrm{c}}$ values obtained from different coatings (see Table 1) it is clear that the barrier effect of a coating increases in the following order: $\mathrm{PrPc}_{2}<\mathrm{SmPc}_{2}<$ $\mathrm{HoPc}_{2}$.

The percent protection efficiency $\left(\eta_{\mathrm{R}} \%\right)$ (see Table 1 ) is related to $R_{\mathrm{po}}$, by the formula:

$$
\eta_{\mathrm{R}} \%=\frac{R_{\mathrm{po}}^{\mathrm{c}}-R_{\mathrm{po}}^{\mathrm{o}}}{R_{\mathrm{po}}^{\mathrm{c}}} \times 100
$$

where $R_{\mathrm{po}}^{\mathrm{o}}$ and $R_{\mathrm{po}}^{\mathrm{c}}$ represent pore resistance for carbon steel coated by alkyd resin only and when including the $\mathrm{LnPc}_{2}$ particles, respectively.

We can see from Table 1 that the alkyd@LnPc $\mathrm{C}_{2}$ nanocomposite coatings provided improved protection efficiency $\eta_{\mathrm{R}} \%$ in acid solution. This confirms that the alkyd@LnPc 2 nanocomposite coatings were effective in protecting the carbon steel when exposed to a $0.5 \mathrm{M} \mathrm{HCl}$ solution.

To corroborate EIS data, the effect of alkyd@LnPc $c_{2}$ nanocomposite coatings on carbon steel corrosion behavior was investigated in a $0.5 \mathrm{M} \mathrm{HCl}$ solution using potentiodynamic polarization (see Fig. 5).

Major polarization parameters, corrosion current density $\left(j_{\text {corr }}\right)$, corrosion potential $\left(E_{\text {corr }}\right)$, and inhibition efficiency $\left(\eta_{\mathrm{j}} \%\right)$ are presented in Table 2 .

The inhibition efficiency $\left(\eta_{\mathrm{j}} \%\right)$ is related to corrosion current density $\left(j_{\text {corr }}\right)$, by the formula:

$$
\eta_{\mathrm{j}} \%=\frac{j_{\text {corr }}^{\mathrm{o}}-j_{\text {corr }}^{\mathrm{c}}}{j_{\text {corr }}^{\mathrm{o}}} \times 100
$$

where $j_{\text {corr }}^{\mathrm{o}}$ and $j_{\text {corr }}^{\mathrm{c}}$ represent the corrosion current density for carbon steel coated by the alkyd resin only and when including the $\mathrm{LnPc}_{2}$ particles, respectively.

From Table 2 it is clear that carbon steel coated by the alkyd@LnPc $c_{2}$ nanocomposite coatings exhibits a decreased $j_{\text {corr }}$, as well as an increased $E_{\text {corr }}$, compared with neat alkyd coating. Further, it was found that the alkyd resin containing $\mathrm{LnPc}_{2}$ particles showed better inhibition efficiency $\eta_{\mathrm{j}} \%$ than the neat alkyd coating (see Table 2).

\subsection{Absorption of $\mathrm{H}_{2} \mathrm{O}$ studies}

$\mathrm{H}_{2} \mathrm{O}$ has a higher dielectric constant $\left(\varepsilon_{\mathrm{H}_{2} \mathrm{O}}=80\right)$ than that of the alkyd one, so the value of $C_{\mathrm{c}}$ with absorbed $\mathrm{H}_{2} \mathrm{O}$ is higher than that of the dry coating. ${ }^{23}$ Information available on the amount of water absorbed by the coating at different stages of exposure $(\varnothing)$ is provided by the Brasher-Kingsbury equation (see eqn (3)). ${ }^{24}$ 
Table 1 EIS parameters for carbon steel coated by alkyd resin only and when including the $\mathrm{LnPc}_{2}$ particles, immersed in $0.5 \mathrm{M} \mathrm{HCl}$ solution at $298 \mathrm{~K}$

\begin{tabular}{|c|c|c|c|c|c|}
\hline Coating type & $R_{\mathrm{po}} \mathrm{k} \Omega \mathrm{cm}^{2}$ & $C_{\mathrm{c}} \times 10^{-8} \mathrm{~F} \mathrm{~cm}^{-2}$ & $R_{\mathrm{ct}} \mathrm{k} \Omega \mathrm{cm}^{2}$ & $C_{\mathrm{dl}} \times 10^{-8} \mathrm{~F} \mathrm{~cm}^{-2}$ & $\eta_{\mathrm{R}} \%$ \\
\hline Neat alkyd coating & 21.8 & 73.5 & 14.6 & 39.2 & - \\
\hline alkyd@PrPc ${ }_{2}$ & 140.2 & 5.6 & - & - & 84.3 \\
\hline alkyd@HoPc 2 & 173.2 & 4.6 & - & - & 87.4 \\
\hline
\end{tabular}

$$
\varnothing=\log \left(C_{t} / C_{0}\right) / \log \varepsilon_{\mathrm{H}_{2} \mathrm{O}}
$$

here $C_{t}$ is the coatings capacitance at time $t, C_{0}$ is the initial coatings capacitance, and $\varepsilon_{\mathrm{H}_{2} \mathrm{O}}$ is the dielectric constant of $\mathrm{H}_{2} \mathrm{O}$ $\left(\varepsilon_{\mathrm{H}_{2} \mathrm{O}}=80\right)$.

The coating capacitance can be measured at different immersion time by fitting the equivalent circuit to the EIS data. Fig. 6 reports on the amount of water $(\varnothing)$ absorbed by the various coatings during different immersion times. It was observed that the alkyd@LnPc $\mathrm{C}_{2}$ nanocomposite coatings gave a lower $\varnothing$ value, when compared to the neat alkyd coating. This would have indicated that the lanthanide bis-phthalocyanine compounds prevent the passage of water and corrosive ions

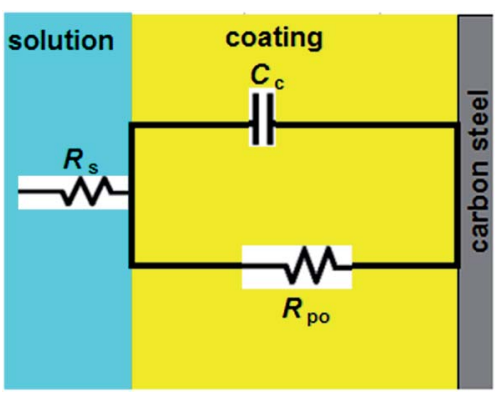

Fig. 4 Equivalent circuit for the alkydaLnPc 2 coatings

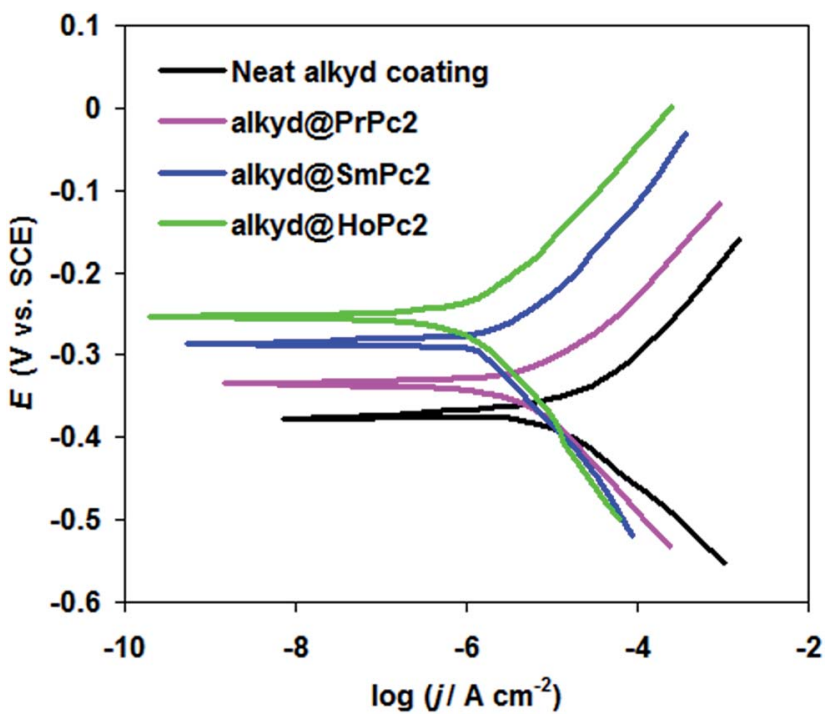

Fig. 5 Potentiodynamic polarization curves for the carbon steel coated with the neat alkyd and alkyd $a \mathrm{LnPC}_{2}$ nanocomposite coatings in $0.5 \mathrm{M} \mathrm{HCl}$ solution at $298 \mathrm{~K}$. throughout the coating layers. The permeability compared to the neat alkyd coating is considerably reduced by the use of $\mathrm{LnPc}_{2}$. A possible explanation one may relate to blocking of the resin pores by the $\mathrm{LnPc}_{2}$ particles and/or repelling of water molecules by the highly hydrophobic $\mathrm{LnPc}_{2}$ species. The lowest water absorption was demonstrated by the alkyd/HoPc ${ }_{2}$ nanocomposite coating.

\subsection{Effect of $\mathrm{LnPc}_{2}$ on physico-mechanical properties}

The adhesion strength of coating is known to play a major role in enhancing of the corrosion protection performance of coatings. $^{25}$

Table 2 The values of corrosion current density, corrosion potential and the corresponding inhibition efficiency for carbon steel coated by alkyd resin only and when including the $\mathrm{LnPc}_{2}$ particles, immersed in $0.5 \mathrm{M} \mathrm{HCl}$ solution at $298 \mathrm{~K}$

\begin{tabular}{|c|c|c|c|}
\hline Coating type & $-E_{\text {corr }} \mathrm{V} v s . \mathrm{SCE}$ & $j_{\text {corr }} \mathrm{A} \mathrm{cm}^{-2}$ & $\eta_{\mathrm{j}} \%$ \\
\hline Neat alkyd coating & 0.377 & $18.97 \times 10^{-6}$ & - \\
\hline alkyd@PrPc & 0.333 & $2.40 \times 10^{-6}$ & 87.3 \\
\hline alkyd@SmPc & 0.285 & $1.76 \times 10^{-6}$ & 90.7 \\
\hline alkyd@HoPc & 0.253 & $1.40 \times 10^{-6}$ & 92.6 \\
\hline
\end{tabular}

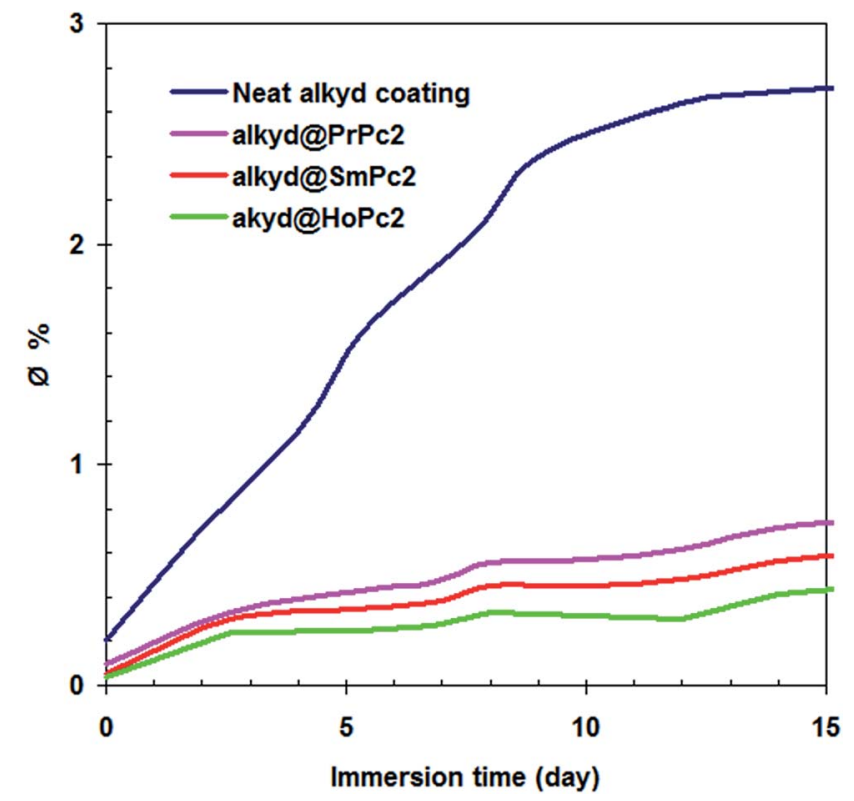

Fig. 6 The water absorption $(\varnothing)$ featured by the investigated coatings as a function of immersion time. 


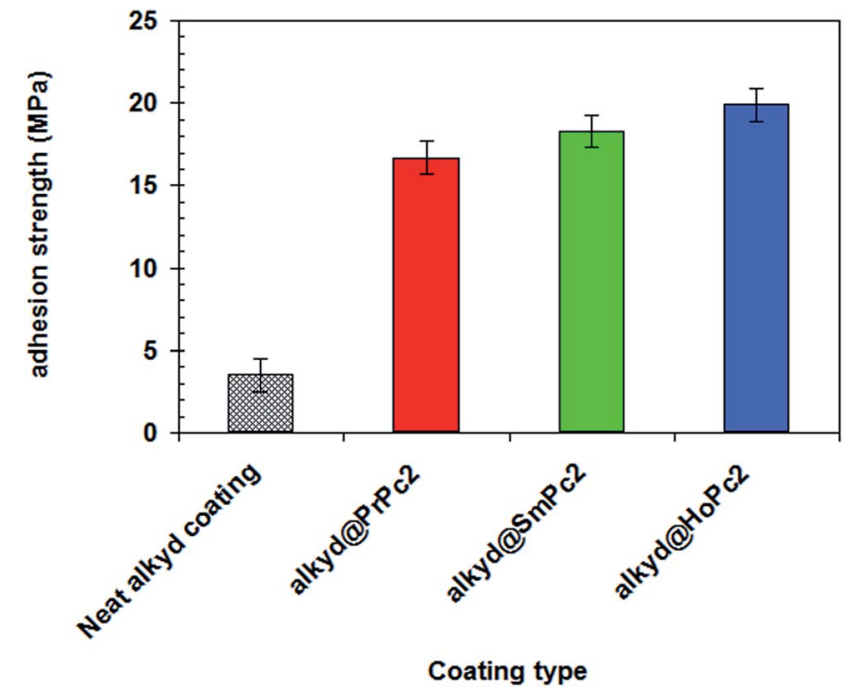

Fig. 7 The effect of $\mathrm{LnPc}_{2}$ on the pull-off adhesion strength of alkyd resin-based coatings.

The effect of $\mathrm{LnPc}_{2}$ on the adhesion strength of alkyd coating was evaluated by pull-off adhesion strength experiments and the results were shown in Fig. 7. As follows from there, incorporation of $\mathrm{LnPc}_{2}$ into the alkyd coating effectively enhanced the adhesion strength of coating. The average adhesion strength of the neat alkyd coating (without $\mathrm{LnPc}_{2}$ ) was $3.34 \mathrm{MPa}$, while significantly higher values of $16.73 \mathrm{MPa}, 18.34 \mathrm{MPa}$ and $19.94 \mathrm{MPa}$ were obtained for alkyd@PrPc$c_{2}$, alkyd@SmPc$c_{2}$ and alkyd@HoPc ${ }_{2}$ composites, respectively. Collectively, these results establish the ability of $\mathrm{LnPc}_{2}$ particles to increase the resistance of a coating to separation from a substrate when a perpendicular tensile force is applied.

The effects of the $\mathrm{LnPc}_{2}$ particles on scratch hardness, impact resistance, bend test and contact angle for alkyd coating behavior were examined and the results are listed in Table 3.

Interestingly, the scratch hardness of the coatings increased by incorporation of $\mathrm{LnPc}_{2}$ particles into the coating. The best scratch hardness was gained by the alkyd@HoPc $\mathrm{H}_{2}$ composite. This improvement in scratch hardness may possibly be related to the restriction of indentation due to the increase in physical interactions between the alkyd resin and $\mathrm{LnPc}_{2}$ particles. ${ }^{26}$

Furthermore, the impact resistance of the alkyd resin coating became evidently improved by doping it with $\mathrm{LnPc}_{2}$ (Table 3). Presumably incorporation of $\mathrm{LnPc}_{2}$ particles within the alkyd resin matrix restricts the chain mobility, thus leading to high impact resistance. ${ }^{26}$

Table 3 Physico-mechanical properties for neat alkyd and alkyd@ $\mathrm{LnPc}_{2}$ nanocomposite coatings

\begin{tabular}{lllll}
\hline Coating type & $\begin{array}{l}\text { Scratch } \\
\text { hardness }(\mathrm{kg})\end{array}$ & $\begin{array}{l}\text { Impact resistance } \\
(\mathrm{kg} \mathrm{cm})\end{array}$ & $\begin{array}{l}\text { Bend } \\
\text { test }\end{array}$ & $\begin{array}{l}\text { Contact } \\
\text { angle }\end{array}$ \\
\hline Neat alkyd coating & 3.5 & 75 & Pass & $92^{\circ}$ \\
alkyd@PrPc & 9.0 & 110 & Pass & $98^{\circ}$ \\
alkyd@SmPc & 10.5 & 131 & Pass & $99^{\circ}$ \\
alkyd@HoPc & 12.2 & 115 & Pass $101^{\circ}$
\end{tabular}

Excellent bend test results were observed also for coatings without film cracks.

The hydrophobic nature of the alkyd@LnPc $c_{2}$ nanocomposites was further characterized through contact-angle measurements. Contact angles determined for the neat alkyd coating, alkyd@PrPc$c_{2}$, alkyd@SmPc 2 and alkyd@HoPc $c_{2}$ were $92^{\circ}, 98^{\circ}, 99^{\circ}$ and $101^{\circ}$, respectively, indicating that all of the alkyd@LnPc $\mathrm{L}_{2}$ coatings were hydrophobic by nature. This means that $\mathrm{LnPc}_{2}$ particles decrease the contact of the coating surface with the corrosive solution leading to an improvement in the anticorrosion behavior of the coatings. ${ }^{27}$

Fig. 8 displays the results of the thermogravimetry analysis (TGA) of the studied coatings. Pure alkyd coating was completely decomposed $(100 \%)$ at $800{ }^{\circ} \mathrm{C}$, while the alkyd@LnPc $\mathrm{C}_{2}$ samples were less decayed $(80 \pm 5 \%)$. This would suggest the addition of $\mathrm{LnPc}_{2}$ into the resin matrix improved the thermal stability of the coatings, presumably due to interaction between $\mathrm{LnPc}_{2}$ particles and the alkyd resin. ${ }^{28}$

\subsection{Morphology studies}

Scanning electron microscopy (SEM) was used to investigate the

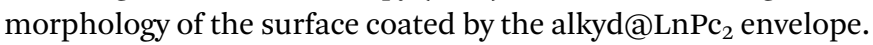
The two carbon steel samples coated by the alkyd resin and the alkyd@LnPc $\mathrm{C}_{2}$ nanocomposites were exposed to a $0.5 \mathrm{M} \mathrm{HCl}$ solution for $168 \mathrm{~h}$. The SEM images are presented in Fig. 9. In the case of the carbon steel coated only by the resin (Fig. 9a), a patterns of small cracks were observed over the coating layer. It is clear then why the coating layer was severely damaged by the corrosive solution. In contrast, the alkyd@LnPc $c_{2}$ coatings (Fig. 9b), featured a much better surface morphology, indicating for a considerable improvement of the coating layer texture by adding $\mathrm{LnPc}_{2}$.

\subsection{Explanation of the role of $\mathrm{LnPc}_{2}$}

Alkyd@LnPc $\mathrm{L}_{2}$ nanocomposite coatings are a class of materials in which $\mathrm{LnPc}_{2}$ particles with nanoscale dimensions are embedded in an alkyd resin matrix. ${ }^{29}$ The small size of $\mathrm{LnPc}_{2}$ particles allowing their even dispersion within the resin matrix

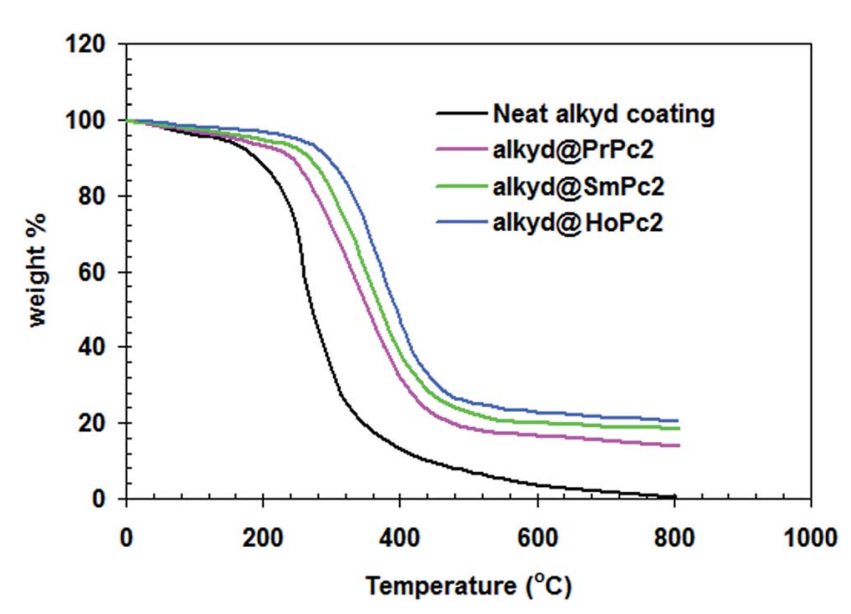

Fig. 8 TGA plot of alkyd@LnPc 2 nanocomposite coatings. 

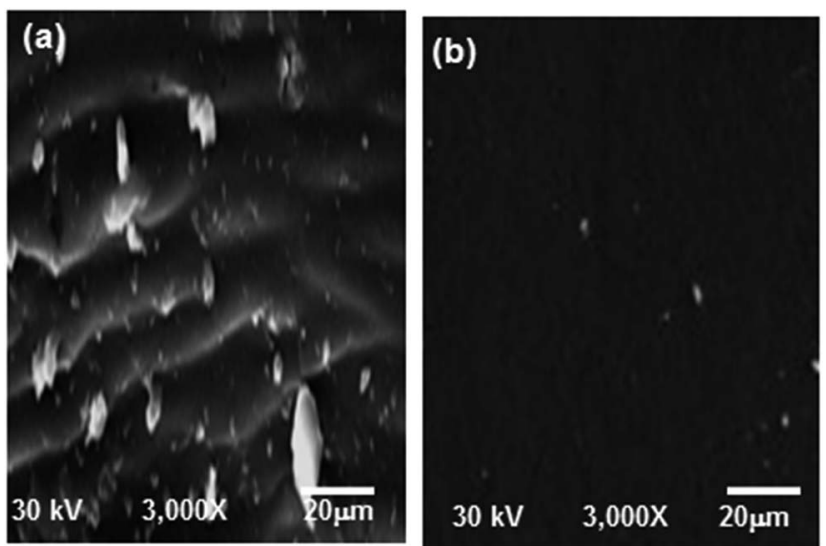

Fig. 9 SEM micrographs of coated carbon steel immersed in $0.5 \mathrm{M}$ $\mathrm{HCl}$ solution at $298 \mathrm{~K}$ for (a) neat alkyd coating and (b) alkyd@ $\mathrm{LnPC}_{2}$ nanocomposite coatings.

may be considered an important issue determining the unique properties of composites involving such compounds. ${ }^{30}$

The general idea concerned with the use of $\mathrm{LnPc}_{2}$ components to produce anti-corrosion coatings was to create a synergy between the various constituents, so that novel properties capable of meeting or exceeding design expectations could be achieved.

In general, alkyd@LnPc $c_{2}$ nanocomposite coatings feature diverse mechanical and electrochemical properties which are different from those of the neat alkyd coating.

The corrosion process in the acid solutions that occurs on the carbon steel surface involves oxidation reaction $\left(\mathrm{Fe}_{(\mathrm{s})} \rightarrow\right.$ $\mathrm{Fe}_{(\mathrm{aq})}{ }^{2+}+2 \mathrm{e}$ ) and one or more reduction reactions. ${ }^{31-34}$ These reactions occur at the metal surface where a corrosion cell has been established. To reduce the corrosion rate it is necessary to control the dynamics of the corrosion process by applying neat alkyd coating on the metal. Such a coating acts as a barrier between the carbon steel and its environment, slowing down the rate at which water, oxygen, or ions from the environment reach the metal surface. ${ }^{35}$ In the alkyd@ $\mathrm{LnPc}_{2}$ nanocomposite coatings, the nano-size particles of $\mathrm{LnPc}_{2}$ are well dispersed in the alkyd resin, thus being able to prevent the diffusion of water, oxygen, and ionic species through the spaces occurring in the resin's matrix.

$\mathrm{LnPc}_{2}$ particles may effectively block the resin's pores (at least to some extent) and in this way reduce the permeability of the nanocomposite. Besides, $\mathrm{LnPc}_{2}$ phthalocyanines are highly hydrophobic and therefore their molecules have a natural potential to repel water species as well as ions solvated by $\mathrm{H}_{2} \mathrm{O}$. Such effects should have reasonably improved the coating's protection efficiency.

The principal reason, which may elucidate the strong adhesion of alkyd@ $\mathrm{LnPc}_{2}$ nanocomposite coatings is definitely related to the magnetic properties of $\operatorname{Ln}(3+)$ ions and hence obviously featured by the $\mathrm{LnPc}_{2}$ particles. Open f-shell cations, including unpaired electrons, are strongly paramagnetic under normal conditions (and some of them become even ferromagnetic $\left.{ }^{36}\right)$ and it is very possible they could effectively interact
Table 4 Effective magnetic moments, $\mu_{\text {eff }}$ (B.M.) of the $\mathrm{Ln}^{3+}$ ions involved in the investigated $\mathrm{LnPc}_{2}$ compounds (experimental data, according to (ref. 33))

\begin{tabular}{llll}
\hline $\mathrm{Ln}^{3+}$ & $\mathrm{Pr}^{3+}$ & $\mathrm{Sm}^{3+}$ & $\mathrm{Ho}^{3+}$ \\
\hline$\mu_{\text {eff }}$ (B.M.) & 3.6 & 1.7 & 10.7 \\
\hline
\end{tabular}

with the ferromagnetic atoms of iron (of the carbon steel) via magnetic field forces. From among the rare earth metals, Ho has the highest magnetic permeability, and the $\mathrm{Ho}^{3+}$ ion exhibits the largest magnetic moment ( $\mu_{\text {eff }}$, B.M.), Table 4. Incidentally, the ferromagnetic performance revealed by the holmium metal is even far better than that of Fe. ${ }^{36}$ Hence, this particular paramagnetic feature is certainly dominant among the factors that might have contributed to reinforcing the contact between the alkyd matrix and the steel core. This conclusion was plausibly confirmed in the pull-off tests which showed the adhesion strength of the alkyd@HoPc ${ }_{2}$ nanocomposite was 6 times as large as found for the alkyd resin alone (Fig. 7).

It must be emphasized, that the statement postulated above well correlates with the results reported in Fig. 2, 5 and 6. From the Nyquist and Bode plots (Fig. 2) follows, that the corrosion mechanism in the respective alkyd@LnPc ${ }_{2}$ coatings seems quite similar, despite some differences in $R_{\mathrm{po}}$ values (averaged increment of $9 \%$ ). On the other hand, in the case of the water absorption process, the differences in $\varnothing$ are more pronounced, but follow the same sequence of coating quality (Fig. 6). Presumably, both $R_{\mathrm{po}}$ and $\varnothing$ values must somehow be related to the adhesion strength of the coating, which determines its stability and hence also the principal properties. Undoubtedly, the paramagnetism of the lanthanides is crucial here, although it is difficult to give a clear-cut explanation for the differences observed between the studied systems. Most probably these may arise from more specific electronic effects occurring at the atomic quantum level, such as the strong spin-orbit coupling featured by the rare earth elements. One may assume, that interaction with the magnetic field generated by the ferromagnetic domains of iron may impose diverse quantum resonance within the "coating-carbon steel" system. Hence, the sequence of the protection efficiency, as evinced by the Pr and Sm composites, must not necessarily comply with the trend demonstrated by the individual magnetic moments, as reported in Table 4.

\section{Conclusions}

Anti-corrosion properties of alkyd resin-based coatings can be improved considerably by the addition of $\mathrm{LnPc}_{2}$ compounds. The newly developed alkyd@LnPc $\mathrm{C}_{2}$ nanocomposite coatings provided excellent protection for carbon steel pipelines. When compared to the neat alkyd matrix, incorporation of $\mathrm{LnPc}_{2}$ particles into the coating system decreases its water permeability and enhances the corrosion resistance and physicomechanical properties. Moreover, the applied $\mathrm{LnPc}_{2}$ dopants significantly raised the adhesion strength of the coating. The 
experimentally determined protection efficiency evidently results from the magnetic properties of the particular $\mathrm{Ln}^{3+}$ ions, and increases in the following order: $\mathrm{PrPc}_{2}<\mathrm{SmPc}_{2}<\mathrm{HoPc}_{2}$. This finding may be considered an important progress in the search for sophisticated anti-corrosion composite systems.

\section{Conflicts of interest}

There are no conflicts to declare.

\section{References}

1 A. Kalendová, I. Sapurina, J. Stejskal and D. Veselý, Anticorrosion properties of polyaniline-coated pigments in organic coatings, Corros. Sci., 2008, 50, 3549-3560.

$2 \mathrm{H}$. Wang and R. Akid, Encapsulated cerium nitrate inhibitors to provide high-performance anti-corrosion sol-gel coatings on mild steel, Corros. Sci., 2008, 50, 1142-1148.

3 H. Vakili, B. Ramezanzadeh and R. Amini, The corrosion performance and adhesion properties of the epoxy coating applied on the steel substrates treated by cerium-based conversion coatings,, Corros. Sci., 2015, 94, 466-475.

4 E. A. Ismail, A. M. Motawie and E. M. Sadek, Synthesis and characterization of polyurethane coatings based on soybean oil-polyester polyols, Egypt. J. Pet., 2011, 20, 1-8.

5 N. Wang, Y. Zhang, J. Chen, J. Zhang and Q. Fang, Dopamine modified metal-organic frameworks on anti-corrosion properties of waterborne epoxy coatings, Prog. Org. Coat., 2017, 109, 126-134.

6 Sh. Ammar, K. Ramesh, B. Vengadaesvaran, S. Ramesh and A. K. Arof, Amelioration of anticorrosion and hydrophobic properties of epoxy/PDMS composite coatings containing nano ZnO particles, Prog. Org. Coat., 2016, 92, 54-65.

7 M. A. Deyab, Effect of carbon nano-tubes on the corrosion resistance of alkydcoating immersed in sodium chloride solution, Prog. Org. Coat., 2015, 85, 146-150.

8 C. Zhang, Y. He, F. Li, H. Di, L. Zhang and Y. Zhan, h-BN decorated with $\mathrm{Fe}_{3} \mathrm{O}_{4}$ nanoparticles through musselinspired chemistry of dopamine for reinforcing anticorrosion performance of epoxy coatings, J. Alloys Compd., 2016, 685, 743-751.

9 M. Behzadnasab, S. M. Mirabedini and M. Esfandeh, Corrosion protection of steel by epoxy nanocomposite coatings containing various combinations of clay and nanoparticulate zirconia, Corros. Sci., 2013, 75, 134-141.

10 M. A. Deyab, K. Eddahaoui, R. Essehli, S. Benmokhtar, T. Rhadfi, A. De Riccardis and G. Mele, Influence of newly synthesized titanium phosphates on the corrosion protection properties of alkyd coating, J. Mol. Liq., 2016, 216, 699-703.

11 M. A. Deyab, A. A. Nada and A. Hamdy, Comparative study on the corrosion and mechanical properties of nanocomposite coatings incorporated with $\mathrm{TiO}_{2}$ nano-particles, $\mathrm{TiO}_{2}$ nano-tubes and $\mathrm{ZnO}$ nano-flowers, Prog. Org. Coat., 2017, 105, 245-251.

12 J. Li, J. Cui, J. Yang, Y. Ma, H. Qiu and J. Yang, Silanized graphene oxide reinforced organo functional silane composite coatings for corrosion protection, Prog. Org. Coat., 2016, 99, 443-451.

13 M. A. Deyab, G. Mele, A. M. Al-Sabagh, E. Bloise, D. Lomonaco, S. E. Mazzetto and C. D. S. Clemente, Synthesis and characteristics of alkyd resin/M-Porphyrins nanocomposite for corrosion protection application, Prog. Org. Coat., 2017, 105, 286-290.

14 S. Radhakrishnan, C. R. Siju, D. Mahanta, S. Patil and G. Madra, Conducting polyaniline-nano- $\mathrm{TiO}_{2}$ composites for smart corrosion resistant coatings, Electrochim. Acta, 2009, 54, 1249-1254.

15 M. A. Deyab, R. Ouarsal, A. M. Al-Sabagh, M. Lachkar and B. El Bali, Enhancement of corrosion protection performance of epoxy coating by introducing new hydrogenphosphate compound, Prog. Org. Coat., 2017, 107, 37-42.

16 M. A. Deyab, A. De Riccardis and G. Mele, Novel epoxy/metal phthalocyanines nanocomposite coatings for corrosion protection of carbon steel, J. Mol. Liq., 2016, 220, 513-517.

17 G. Mele, E. Garci 'a-Lo `pez, L. Palmisano, G. Dyrda and R. Słota, Photocatalytic Degradation of 4-Nitrophenol in Aqueous Suspension by Using Polycrystalline $\mathrm{TiO}_{2}$ Impregnated with Lanthanide Double-Decker Phthalocyanine Complexes, J. Phys. Chem. C, 2007, 111, 6581-6588.

18 S. González, I. C. Mirza Rosca and R. M. Souto, Investigation of the corrosion resistance characteristics of pigments in alkyd coatings on steel, Prog. Org. Coat., 2001, 43, 282-285.

19 M. A. Deyab, The influence of different variables on the electrochemical behavior of mild steel in circulating cooling water containing aggressive anionic species, $J$. Solid State Electrochem., 2009, 13, 1737-1742.

20 M. A. Deyab, N. H. Mohamed and Y. M. Moustafa, Corrosion protection of petroleum pipelines in $\mathrm{NaCl}$ solution by microcrystalline waxes from waste materials: Electrochemical studies, Corros. Sci., 2017, 122, 74-79.

21 M. A. Deyab, Corrosion protection of aluminum bipolar plates with polyaniline coating containing carbon nanotubes in acidic medium inside the polymer electrolyte membrane fuel cell, J. Power Sources, 2014, 268, 50-55.

22 M. A. Deyab and S. T. Keera, Effect of nano-TiO ${ }_{2}$ particles size on the corrosion resistance of alkyd coating, Mater. Chem. Phys., 2014, 146, 406-411.

23 J. R. Macdonald, Impedance Spectroscopy; Emphasizing Solid Materials and Systems, Wiley-Interscience Publications, 1987.

24 D. M. Brasher and A. H. Kingsbury, Electrical measurements in the study of immersed paint coatings on metal. I. Comparison between capacitance and gravimetric methods of estimating water-uptake, J. Appl. Chem., 1954, 4, 62-72.

25 S. P. Tambe, S. K. Singh, M. Patri and D. Kumar, Effect of pigmentation on mechanical and anticorrosive properties of thermally sprayable EVA and EVAl coatings, Prog. Org. Coat., 2011, 72, 315-320.

26 O. ur Rahman and S. Ahmad, Physico-mechanical and electrochemical corrosion behavior of soy alkyd/ $\mathrm{Fe}_{3} \mathrm{O}_{4}$ nanocomposite coatings, RSC Adv., 2014, 4, 14936-14947. 
27 J. A. Syed, S. Tang and X. Meng, Super-hydrophobic multilayer coatings with layer number tuned swapping in surface wettability and redox catalytic anti-corrosion application, Sci. Rep., 2017, 7, 4403.

28 S. K. Dhoke, R. Bhandari and A. Khanna, Effect of nano-ZnO addition on the silicone-modified alkyd-based waterborne coatings on its mechanical and heat-resistance properties, Prog. Org. Coat., 2009, 64, 39-46.

29 V. Mittal, Polymer Nanocomposite Coatings, CRC Press, Taylor \& Francis Group, 2013.

30 N. Nensala and T. Nyokong, Photocatalytic properties of neodymium diphthalocyanine towards the transformation of 4-chlorophenol, J. Mol. Catal. A: Chem., 2000, 164, 69-76.

31 M. A. M. Deyab, Corrosion inhibition and adsorption behavior of sodium lauryl ether sulfate on 180 carbon steel in acetic acid solution and its synergism with ethanol, J. Surfactants Deterg., 2015, 18, 405-411.
32 M. A. Deyab, Inhibition activity of Seaweed extract for mild carbon steel corrosion in saline formation water, Desalination, 2016, 384, 60-67.

33 A. M. Al-Sabagh, N. M. Nasser, O. E. El-Azabawy and A. E. ElTabey, Corrosion inhibition behavior of new synthesized nonionic surfactants based on amino acid on carbon steel in acid media, J. Mol. Liq., 2016, 219, 1078-1088.

34 M. A. Deyab, B. El Bali, R. Essehli, R. Ouarsal, M. Lachkar and $\mathrm{H}$. Fuess, $\mathrm{NaNi}\left(\mathrm{H}_{2} \mathrm{PO}_{3}\right)_{3} \cdot \mathrm{H}_{2} \mathrm{O}$ as a novel corrosion inhibitor for X70-steel in saline produced water, J. Mol. Liq., 2016, 216, 636-640.

35 X. H. Xu, Z. Z. Zhang, F. Guo, J. Yang and X. T. Zhu, Fabrication of superhydrophobic binary nanoparticles/ PMMA composite coating with reversible switching of adhesion and anticorrosive property, Appl. Surf. Sci., 2011, 257, 7054-7060.

36 N. N. Greenwood and A. Earnshaw, Chemistry of the Elements, Butterworth-Heinemann, 2nd edn, 1997, p. 1243. 